\title{
Scaling issues in multi-criteria evaluation of combinations of measures for integrated river basin management
}

\author{
Jörg Dietrich \\ Institute of Water Resources Management, Hydrology and Agricultural Hydraulic Engineering, Leibniz \\ Universität Hannover, Hannover, 30167, Germany
}

Correspondence to: Jörg Dietrich (dietrich@iww.uni-hannover.de)

Published: 12 May 2016

\begin{abstract}
In integrated river basin management, measures for reaching the environmental objectives can be evaluated at different scales, and according to multiple criteria of different nature (e.g. ecological, economic, social). Decision makers, including responsible authorities and stakeholders, follow different interests regarding criteria and scales. With a bottom up approach, the multi criteria assessment could produce a different outcome than with a top down approach. The first assigns more power to the local community, which is a common principle of IWRM. On the other hand, the development of an overall catchment strategy could potentially make use of synergetic effects of the measures, which fulfils the cost efficiency requirement at the basin scale but compromises local interests. Within a joint research project for the $5500 \mathrm{~km}^{2}$ Werra river basin in central Germany, measures have been planned to reach environmental objectives of the European Water Framework directive (WFD) regarding ecological continuity and nutrient loads. The main criteria for the evaluation of the measures were costs of implementation, reduction of nutrients, ecological benefit and social acceptance. The multi-criteria evaluation of the catchment strategies showed compensation between positive and negative performance of criteria within the catchment, which in the end reduced the discriminative power of the different strategies. Furthermore, benefit criteria are partially computed for the whole basin only. Both ecological continuity and nutrient load show upstream-downstream effects in opposite direction. The principles of "polluter pays" and "overall cost efficiency" can be followed for the reduction of nutrient losses when financial compensations between upstream and downstream users are made, similar to concepts of emission trading.
\end{abstract}

\section{Introduction}

The Werra river basin is situated in central Germany within the upper part of the Weser catchment. Before German reunification it was divided by the inner-German borderline. The main industry in the catchment is potash mining, associated with a high salt load of the Werra River. Like for many German rivers, the morphological conditions of the river courses and the ecological continuity were affected before implementation of the European Water Framework Directive (WFD). Agricultural land use dominates in the NorthEastern area of the catchment. In former Eastern Germany many dispersed settlements were not connected to the public sewer system and were often not equipped with decentral- ized wastewater treatment. While the degree of connection was $98 \%$ in Hessen, it was $48 \%$ in the Thuringian part of the Werra catchment in 2001. As a consequence, the nutrient load of the catchment was high compared to the relatively extensive land use and the low population density. The ecological community was degraded in several water bodies, showing a good ecological status according to the AQEM assessment system (Hering et al., 2004) only in upstream regions of the Thuringian Forest.

For the implementation of the WFD, an exemplary river basin management plan (RBMP) was elaborated by an interdisciplinary research team, supported by local water authorities (Dietrich and Schumann, 2006). The RBMP provided several alternative strategies for the catchment, which 
were prepared for a final decision procedure supported by a multi criteria decision support system (Dietrich et al., 2007). Within this paper we focus on spatial aspects of measures for the improvement of the hydro-morphological conditions and the reduction of nutrient loads from point sources and diffuse sources (for a detailed description see Dietrich and Funke, 2009).

One of the challenges in spatial decision analysis is the spatial aggregation of criteria. For an RBMP, measures are located throughout the catchment area. The criteria for the individual measures can be aggregated in space to get an overall multi-criteria assessment of alternative combinations for the RBMP. This technique was applied in the widely used MULINO-DSS (Giupponi et al., 2002). Alternatively the multi-criteria analysis (MCA) can be applied for each of the locations separately, and then the outcome of the MCA is aggregated in space. Both pathways of aggregation of criteria and space can lead to different overall results (Herwijnen and Rietveld, 1999). The first path better represents the characteristics of the basin, whereas the second path allows different preference structures for the smaller sub-units, hence better represents the local situation. By aggregating criteria, positive and negative effects can be smoothened, with the consequence of reduced distinctive character of the alternatives. This kind of spatial compensation can be addressed by introducing additional criteria as Nijssen and Schumann (2014) showed for flood risk management. In this study, we present a strategic combination approach, which includes a criterion for social acceptance of the measures in order to represent the stakeholders' preference for the local measures.

\section{Werra catchment diagnosis and integrated planning of measures for the WFD implementation}

\subsection{Morphological state and nutrient emissions}

The ecological assessment with AQEM showed significant deviations from the species composition, which could be expected for the types of water bodies in that catchment. The salt load of the lower Werra River was not subject of the investigations even if it was known that it is one of the causes of ecological degradation for the affected water bodies. Apart from this, morphological deficits in most river courses (Fig. 1) were identified as a major problem to address in river basin management (Dietrich and Schumann, 2006), hence in the implementation of the Water Framework Directive. The morphological deficits include the riparian and river bed structure, but also numerous structures from groundsills to reservoir dams which disturb or prevent fish migration. Also the overall saprobial state (Fig. 1), as well as nitrate and phosphorus concentrations were found to be beyond the levels which support a good ecological state according to the WFD. The quantitative investigation of the nutrient cycle was done with a chain of models, combining an agricultural production model to compute nutrient losses from agricultural
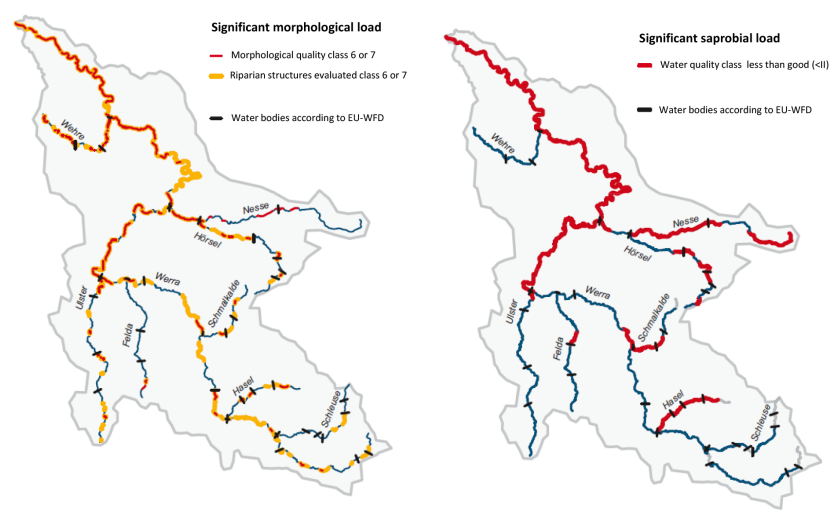

Figure 1. Significant morphological alterations (left) and significant saprobial load (right), indicating priority areas for measures (changed from Dietrich and Schumann, 2006).

areas, a point source emission model for sewage treatment, and a coupled SWAT-RWQM1 model to simulate nutrient turnover and transport at catchment scale. The emissions of nitrogen and phosphorus from point and non-point sources show an uneven distribution over the catchment, closely related with urban land use in the case of point sources (Fig. 2) and agricultural land use in the case of diffuse (non-point) sources (Fig. 3).

\subsection{Development of alternative environmental measures}

The objective of river basin management according to the WFD is to reach a good ecological state of all water bodies by 2015 , with some possible exemptions e.g. for heavily modified water bodies or due to long lasting sanitation or disproportionate costs. The WFD gives a framework for the development and 6-yearly update of river basin management plans (RBMP). The RBMP collects all measures, which were decided by the respective bodies. Within the Werra project, an exemplary RBMP was developed to address the environmental issues of the catchment that were introduced in Sect. 2.1. Different from the formal and final WFD RBMP, in this paper we provide alternative solutions for the selection phase of the decision process, which means that we present not a single solution but alternative measures, which follow the same overall objective. The following types of measures were considered and then designed for the water bodies in order to fulfil the objectives of the WFD:

- Improvement of the morphological conditions of the river

- Ecological continuity by removing barriers or building fish passes

- Creation of riparian buffer strips

- Plantation of natural woods along the rivers

- Removing bank reinforcement 

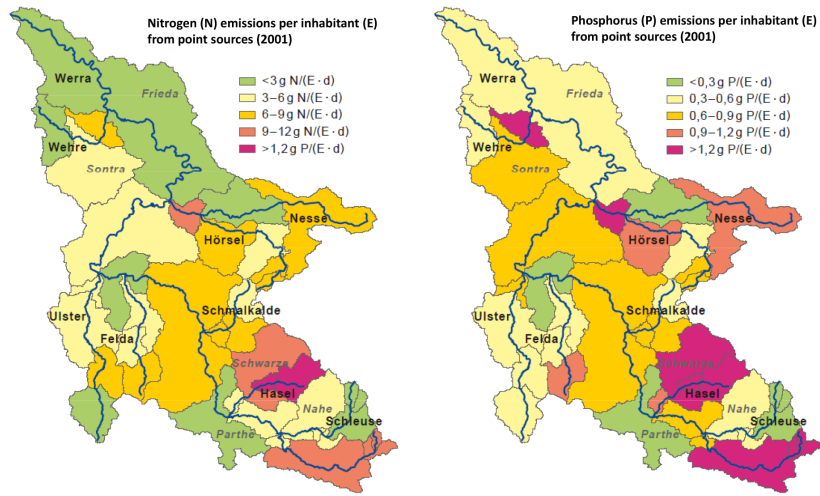

Figure 2. Nitrogen emissions (left) and Phosphorus emissions (right) from point sources, indicating priority areas for measures (changed from Dietrich and Schumann, 2006).

- Removing of canalization

- Reduction of nutrient pollution from diffuse sources

- Conversion of arable land to permanent grassland

- Reduction of fertilizer use

- Optimization of crop rotation

- Reduction of nutrient pollution from point sources

- Connect dispersed settlements to sewage system

- New stage of expansion of treatment plants

- Increase capacity of sewage treatment plants

- Construct new sewage treatment plants

\subsection{Multi-criteria assessment of measures}

All measures were evaluated with the following methods and criteria (Dietrich and Schumann, 2006):

Ecology: the WFD formulates aspiration levels for ecological criteria. If all combinations of measures for the RBMP can reach the objectives, there is no degree of freedom, which justifies an ecological decision criterion. Nevertheless, overfulfillment of the ecological status (very good status instead of good) provides an additional value and could be formulated as criterion. Furthermore, making use of WFD exemptions reduces the ecological value of the measures, which again justifies a decision criterion. In this study, all measures were planned to reach the aspiration levels only, and exemptions were negotiated separately. Thus, we do not investigate purely ecological criteria for the spatial aggregation issue. Ecological consequences of the implementation of measures were included in the ecological benefit analysis, which is human centred and expressed in monetary units.

Ecological benefit: the total economic value (TEV, Turner et al., 2003) includes use-values and non-use values of natural systems. All future values were discounted. We assumed a project lifetime of 20 years.
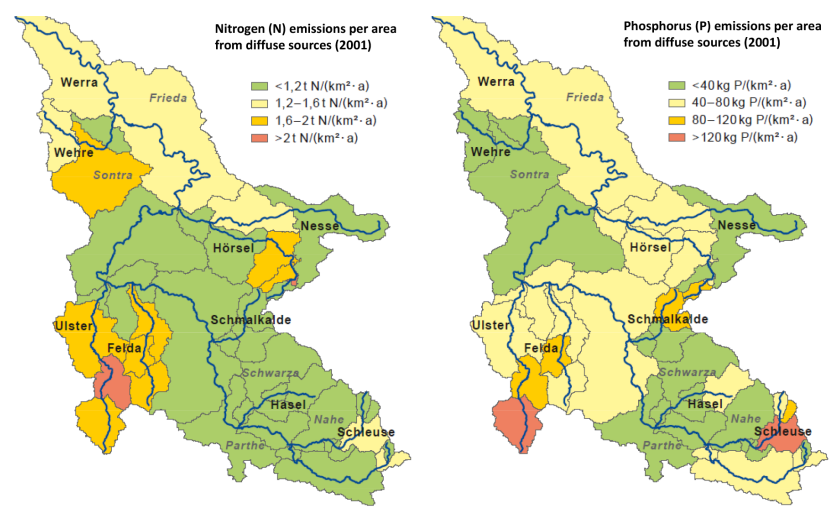

Figure 3. Nitrogen emissions (left) and Phosphorus emissions (right) from diffuse sources, indicating priority areas for measures (changed from Dietrich and Schumann, 2006).
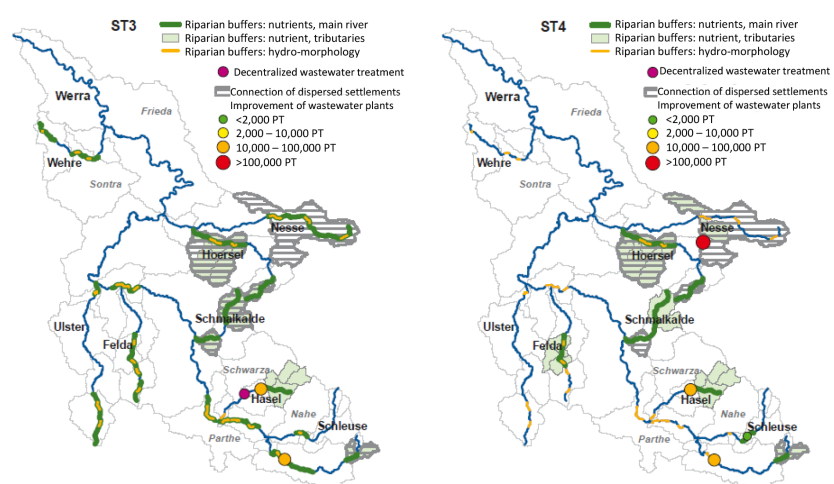

Figure 4. Priority areas for actions within the two strategies focussing on polluter pays principle (ST3, left) and cost-efficiency (ST4, right). PT is the total sewage plant capacity of population equivalent (changed from Dietrich and Schumann, 2006, ST1 and ST2 are shown in Dietrich and Funke, 2009).

Costs: the calculation of the costs of measures is based on literature values. All future costs were discounted.

Reduction of nutrient loads: the effect of measures targeting point sources and diffuse sources was simulated with a model chain agro-economy - eco-hydrology (SWAT) - water quality (RWQM). This included the implementation of typical crop rotations and application of organic and inorganic fertilizer and the change of crop management according to the measures as described in Sect. 2.2. We evaluated the reduction of the total mass of nutrients ( $\mathrm{N}$ and $\mathrm{P}$ ) within the catchment and the fulfilment of the requirements of a good ecological state within the water bodies.

Social acceptance: the Werra research project could not perform a complete participatory planning and decision making process. Nevertheless, the management of conflicts between stakeholders and the acceptance of measures among stakeholders should be regarded in the exemplary RBMP. Thus, a "cooperation index" was developed as a concept to represent the preference structure of stakeholders as a so- 
Table 1. Categories and scales of the ecological benefit criterion (changed from Dietrich and Schumann, 2006).

\begin{tabular}{llll}
\hline Effects of measures & $\begin{array}{l}\text { Conserving/improving } \\
\text { biodiversity }\end{array}$ & $\begin{array}{l}\text { Improving ecological } \\
\text { quality of rivers }\end{array}$ & Recreation \\
\hline Benefit category & $\begin{array}{l}\text { Non-use value, indirect } \\
\text { use value }\end{array}$ & $\begin{array}{l}\text { Use value; Indirect use } \\
\text { value }\end{array}$ & Direct use value \\
\hline Scale & $\begin{array}{l}\text { Water body, } \\
\text { catchment }\end{array}$ & $\begin{array}{l}\text { Single measure, water } \\
\text { body, catchment }\end{array}$ & $\begin{array}{l}\text { Water body, } \\
\text { catchment }\end{array}$ \\
\hline Evaluation technique & Benefit transfer & Replacement costs & Benefit transfer \\
\hline Unit & $\begin{array}{l}\text { Willingness to pay in } € \\
\text { per household }\end{array}$ & $\begin{array}{l}\text { Replacement value in } € \\
\text { per ha riparian zone }\end{array}$ & $\begin{array}{l}\text { Willingness to pay in } € \\
\text { per visit } * \text { number of } \\
\text { visitors }\end{array}$ \\
\hline
\end{tabular}

cial criterion within the decision process, and up to the highest level of aggregation. Based on a dynamic actor network analysis, the index is computed from questionnaires obtained from a representative group of stakeholders of different sectors (tourism, agriculture, nature protection, fishers). These expressed their general acceptance of the measures listed in Sect. 2 before measures were planned in detail. The cooperation index incorporates (a) the degree of being affected by potential measures; (b) the acceptance of the potential measures; (c) the relevance of the affected uses in the region and (d) the question of who will bear the costs (Hirschfeld et al., 2005; Dietrich and Schumann, 2006).

\section{Combination of measures to catchment scale strategies}

The final result of the project's planning are several alternative combinations of measures for the RBMP, which can be used as a decision matrix for multi-criteria evaluation and computation of a ranking based on preferences for the different criteria. This final matrix is computed for the entire Werra catchment. The aggregation of criteria from locations (single measures) via water bodies and their contributing catchments up to the catchment scale was complex and hat to be treated differently for the different criteria. For that reason, the pathway of aggregating criteria first was not possible. We decided to build combinations of measures according to different principles of strategic planning and policy making. Thus we called the final alternatives "strategies".

The aggregation of the criteria introduced in Sect. 2.3 faced the following issues:

Ecology: morphological riverbed improvement was mostly assessed local for single measures (creating or improving habitat structures), but there can be additional ecological effects at larger scale by habitat connectivity. The ecological continuity is very important for long distance travelling fishes. Therefore measures are most effective from downstream to upstream, whereas single measures in the middle of the catchment have reduced value when downstream connectivity is not given.

Ecological benefit: the TEV calculation includes components, which could not be obtained at the scale of single measures or water bodies, in particular by applying the benefit transfer from other studies (Table 1). This includes a superadditive benefit for developing the whole basin into a good ecological status.

Costs were attributed to single measures and aggregated by summation.

Reduction of nutrient loads: the transport of nutrients in the river network can have basin wide effects of measures. Upstream measures are more effective because they also reduce the inflow load of downstream areas. Here, the aggregation can not only count the criteria at the locations where the measures take place. With the model chain, it was possible to calculate basin wide effects of measures. Due to complex interactions in nutrient conversion and retention processes, the effects of upstream measures on downstream regions cannot be quantified separately for single measures. Thus the model performs the aggregation, and the final catchment outflow was taken as aggregated consequence of the different strategies for nutrient reduction.

Social acceptance: for getting a representative number of questionnaires, this kind of analysis could not be done separately for the single measures or water bodies. Even if the index value could be assigned for the measures within a water body, the cooperation potential cannot be related to the sub-set of stakeholders living in the respective water body sub-catchment.

The complexity of the problem does not allow a spatial multi-criteria aggregation at smaller scales than the overall catchment. Otherwise, much more detailed studies had to be performed regarding the ecological benefit and the social criteria. Furthermore, a decomposition of the upstream - downstream effects of nutrient reduction had to be done. As a consequence, we performed a coordinated catchment strategy development. This follows the following principles: 
Table 2. Four catchment management strategies and respective decision criteria (from Dietrich and Funke, 2009; Dietrich and Schumann, 2006).

\begin{tabular}{|c|c|c|c|c|c|}
\hline Strategy & $\begin{array}{l}\text { Cost (mill. } € \text { ) point } \\
\text { sources/non-point } \\
\text { sources/total incl. } \\
\text { morphology }\end{array}$ & $\begin{array}{l}\text { Total phosphorus } \\
\text { reduction }(t / a)\end{array}$ & $\begin{array}{l}\text { Ecological benefit } \\
\text { (mill. } € \text { ) }\end{array}$ & $\begin{array}{l}\text { Cooperation index } \\
\text { (polluter bears } \\
\text { costs, higher } \\
\text { values show more } \\
\text { conflicts) }\end{array}$ & $\begin{array}{l}\text { Number of water } \\
\text { bodies with } \\
\text { extended need for } \\
\text { monitoring }\end{array}$ \\
\hline ST1 & $9.2 / 2.8 / 56.0$ & 32.0 & 104.3 & 2.07 & 10 \\
\hline ST2 & $6.3 / 13.9 / 64.2$ & 30.1 & 112.1 & 1.73 & 10 \\
\hline ST3 & 7.0/8.1/102.3 & 33.6 & 118.1 & 2.73 & 11 \\
\hline ST4 & $4.8 / 6.6 / 55.6$ & 32.6 & 127.2 & 1.80 & 13 \\
\hline
\end{tabular}

$S T 1$ : first reduce point sources, then diffuse sources - the idea is a lower cost and better predictability of the consequences of measures at point sources;

ST2: first reduce diffuse sources, then point sources - the idea is to make use of combined beneficial effects from reducing diffuse sources by hydro-morphological structures like riparian buffers;

ST3: polluter oriented distribution of measures - the idea is to strictly follow the "polluter pays" principle;

ST4: most cost efficient allocation of measures - the idea is an economic optimization of the overall RBMP.

All the four basic strategies were computed and all criterion values were calculated with the respective methods. For the ecological benefit, the willingness to pay for biodiversity was calculated with a declining value. The measures for ecological continuity prefer the removal of structures where possible. Table 2 shows the results of the overall assessment.

The polluter oriented strategy ST3 does not only show the highest costs, but also the highest conflict potential because farmers expressed negative about the planned measures (Table 2). The optimized strategy ST4 is marginally cheaper than ST1, but shows better ecological benefit due to high valued riparian buffers. But, ecologists estimated that 13 instead of 10 resp. 11 water bodies need extended monitoring due to a marginal fulfilment of the ecological objectives, which (under uncertainty) can lead to the need for additional measures.

\section{Conclusions}

The results of the simulation and aggregation of criteria highlight problems in following the "polluter pays" principle and the WFD requirement of overall "cost efficiency of the program of measures" for the RBMP at the same time. A decomposition of larger scale measures and the redistribution of costs for measures with basin wide effects could be done by concepts like emission trading for nutrients. Then, the cost recovery happens at the polluters, but the spatial aggregation effects of nutrient reduction can be utilized in the best way.

Further work will be done in comparing different aggregation methods and different MCA methods. For very large basins, the study could be designed differently - e.g. the Werra basin is one part of the Weser basin, and the Fulda basin and the middle Weser and lower Weser sub-basins could be assessed separately. Then, the four larger parts of the whole basin could be aggregated in both ways (first space or first criteria).

Acknowledgements. This work is based on results of the joint research project "River Basin Management of the Werra River" (principal investigator: Andreas Schumann, Bochum). The German Federal Ministry of Education and Research (Bundesministerium für Bildung und Forschung, BMBF, FKZ 0330211) is acknowledged for funding of the project and the book publication of the results. We would like to thank all those involved in the original project for their collaborative efforts and for sharing data, knowledge and results.

\section{References}

Dietrich, J. and Schumann, A. H. (Eds.): Werkzeuge für das integrierte Flussgebietsmanagement - Ergebnisse der Fallstudie Werra, Konzepte für die nachhaltige Entwicklung einer Flusslandschaft Bd. 7, Weissensee-Verlag, Berlin, 470 S., 2006.

Dietrich, J., Schumann, A. H., and Lotov, A. V.: Workflow oriented participatory decision support for integrated river basin planning, in: Topics on System Analysis and Integrated Water Resource Management (IWRM), edited by: Castelletti, A. and Soncini Sessa, R., Elsevier, 2007.

Dietrich, J. and Funke, M.: Integrated catchment modelling within a strategic planning and decision making process: Werra case study, J. Phys. Chem. Earth, 34, 580-588, doi:10.1016/j.pce.2008.11.001, 2009.

Giupponi, C., Mysiak, J., Fassio, A., and Cogan, V.: Towards a spatial decision support system for water resource management: MULINO-DSS 1st release. Proceedings 5th AGILE Conference on Geographic Information Science, Palma (Spain), 25-27 April, 2002.

Hering, D., Moog, O., Sandin, L., and Verdonschot, P. F. M.: Overview and application of the AQEM assessment system, Hydrobiologia, 516, 1-20, 2004. 
Herwijnen, v. M. and Rietveld, P.: Spatial dimensions in multicriteria analysis, in Thill, J.-C.: Spatial multicriteria decision making and analysis, Ashgate, 77-102, 1999.

Hirschfeld, J., Dehnhardt, A., and Dietrich, J.: Socioeconomic analysis within an interdisciplinary spatial decision support system for an integrated management of the Werra River Basin, Limnologica, 35, 234-244, 2005.
Nijssen, D. and Schumann, A. H.: Aggregating spatially explicit criteria: avoiding spatial compensation, International Journal of River Basin Management, 12, 87-98, 2014.

Turner, R. K., Paavola, J., Cooper, P., Farber, S., Jessamy, V., and Georgiou, S.: Valuing Nature: lessons learned and future research directions, Ecol. Econom., 46, 493-511, 2003. 